\title{
Study on the Impact of Comprehensive Urbanization on Urban Civil Building CO2 Emissions in China
}

\section{Rong Guo}

Dalian University of Technology

\section{Nan Li}

Dalian University of Technology

Hailin Mu ( $\sim$ mhldut@126.com)

Dalian University of Technology https://orcid.org/0000-0003-3322-3836

\section{Ming Zhang}

China University of Mining and Technology

\section{Xiyue Yang}

Dalian University of Technology

\section{Yixuan Han}

Dalian University of Technology

\section{Rongkang Yao}

Dalian University of Technology

\section{Zhihao Shao}

Dalian University of Technology

\section{Research Article}

Keywords: Urban civil buildings, Carbon emissions, Comprehensive Urbanization, Entropy method, Spatial effects, SDM

Posted Date: July 7th, 2021

DOI: https://doi.org/10.21203/rs.3.rs-590889/v1

License: (c) This work is licensed under a Creative Commons Attribution 4.0 International License. Read Full License

Version of Record: A version of this preprint was published at Environmental Science and Pollution Research on October 21st, 2021. See the published version at https://doi.org/10.1007/s11356-02116595-3. 
Study on the impact of comprehensive urbanization on urban civil building $\mathrm{CO}_{2}$ emissions in

\section{China}

Rong Guo a, Nan Li $^{\text {a }}$, Hailin Mu ${ }^{\text {a }}$, Ming Zhang ${ }^{\mathrm{b}}$, Xiyue Yang ${ }^{\mathrm{a}}$, Yixuan Han ${ }^{\mathrm{a}}$, Rongkang Yao ${ }^{\mathrm{a}}$, Zhihao Shao ${ }^{\mathrm{a}}$

a Key Laboratory of Ocean Energy Utilization and Energy Conservation of Ministry of Education, Dalian University of Technology, Dalian, 116024, China

${ }^{\mathrm{b}}$ School of Economics and Management, China University of Mining and Technology, Xuzhou, 221116, China

*Corresponding author: Hailin Mu, 13889528085, hailinmu@dlut.edu.cn

E-mail address:

(R. Guo), nanli@mail.dlut.edu.cn

(N. Li), hailinmu@,dlut.edu.cn

(H. $\mathrm{Mu})$, zhangmingdlut@163.com (M. Zhang), yangxiyue513@mail.dlut.edu.cn (X. Yang), hanoeseom@mail.dlut.edu.cn (Y. Han), yaorongkang@mail.dlut.edu.cn (R. Yao), szh343114335@mail.dlut.edu.cn (Z. Shao)

\section{Abstract}

With the rapid development of China, urbanization has become an important research topic of China's $\mathrm{CO}_{2}$ emissions. To fill the gap in considering the spatial correlation of the comprehensive urbanization that includes multi-dimensional factors on $\mathrm{CO}_{2}$ emissions from the operation phase of urban civil buildings (ubec). This study constructs a comprehensive evaluation indicator of urbanization from four aspects including population, economy, society and land urbanization by using the entropy method. The spatial spillover effect of ubec and the impact of comprehensive urbanization on $\boldsymbol{u b e c}$ are also studied by using the spatial panel model in this paper. This study finds out that $\boldsymbol{u b e c}$ has obvious spatial spillover effects. During the early years of the study period, the eastern coastal areas had greater carbon emissions, while in recent years they have gradually transitioned to the northwestern regions. Comprehensive urbanization has a significant promotion effect on it. And foreign direct investment and per capita energy consumption also have positive impact on $\boldsymbol{u b e c}$. This study provides a reference for measuring the effects of urbanization on sector-specific $\mathrm{CO}_{2}$ emissions and maybe useful for energy efficiency and emission abatement efforts in China. 
Declarations:

\section{Ethics approval and consent to participate}

Not applicable

\section{Consent for publication}

$39 \quad$ Not applicable

\section{Availability of data and materials}

The datasets analysed during the current study are available in the [Statistical Yearbook Of China and China Energy

43 Statistical Yearbook] repository, [http://www.stats.gov.cn]

\section{Competing interests}

The authors declare that they have no competing interests.

\section{Funding}

The financial support from the National Natural Science Foundation of China (No. 51976020, 71603039).

\section{Authors' contributions}

Conceptualization, N.L.; methodology, N.L., M.Z., X Y., and R.G.; software, R.G.; validation, R.G.; formal analysis, R.G.; data curation, R.G.; writing—original draft preparation, R.G.; writing—review and editing, Y.H.,

R.Y. and Z.S.; supervision, H.M. All authors have read and agreed to the published version of the manuscript.

\section{Acknowledgements}

We gratefully acknowledge the financial support from the National Natural Science Foundation of China (No. 51976020, 71603039).

59 
With the rapid pace of economic development, terrible side effects such as severe polluting problems are caused worldwide by abusing and overusing coal and fossil fuel (Pang et al. 2021, Zhu et al. 2020). People are increasingly concerned about global warming. $\mathrm{CO}_{2}$ emissions in greenhouse gases are the main factor of climate change (Yang et al. 2021). Therefore, decreasing $\mathrm{CO}_{2}$ emissions has been one of the key tasks for countries around the world. And China is one of the world's largest carbon producers (Chen et al. 2020). From an end-use of energies perspective, industry, transport, and construction are listed as the three industries with the largest energy consumption. The Intergovernmental Panel on Climate Change (IPCC) reveals that buildings are estimated to account for $31 \%$ of the world' s total energy-related $\mathrm{CO}_{2}$ emissions by 2020 , rising to $52 \%$ by 2050 (Hou et al. 2021). The $\mathrm{CO}_{2}$ emissions from China's construction have grown from 668 million tons to 2.04 billion tons between 2000 and 2017, which is approximately $17-21 \%$ of the $\mathrm{China}^{\mathrm{s}} \mathrm{CO}_{2}$ emissions ( $\mathrm{Li}$ et al. 2021). In the lifetime of a building, $\mathrm{CO}_{2}$ emissions from the operation phase of buildings contribute to $2 / 3$ of the total $\mathrm{CO}_{2}$ emissions from building, the majority of them from urban buildings (Mengjie 2019). As the economy grows and urbanization accelerates, these numbers are on the rise. To reach China's commitment to reduce carbon emissions intensity by $60-65 \%$ by 2030 compared to 2005 (Chen et al. 2020, Wu et al. 2020), the problem of reducing carbon emissions from the operation phase of buildings needs to be resolved urgently.

China is in a phase of rapid urbanization. The direct effects of urbanization are the concentration of urban population, the aggregation of land use, and the clustering of economic activities. (Huo et al. 2021). Based on the urbanization rate represented by the proportion of urban population, China's urbanization rate increases from $17.92 \%$ in 1978 to $60.6 \%$ in 2019 (Lin \&Zhu 2021). It can be seen that urbanization is a critical influence on $\mathrm{CO}_{2}$ emissions from buildings. Regarding urbanization research, most of the urbanization is characterized by the ratio of the urban population. But from the current point of view, urbanization is multifaceted, and if it is only studied from the perspective of the population, it may be relatively single. Most of the existing studies on the effects of urbanization on the $\mathrm{CO}_{2}$ emissions of buildings have been conducted on the entire life cycle of buildings. Due to the entire life cycle of the building, the operating phase accounts for a relatively large proportion. It is important to study the changes of $\mathrm{CO}_{2}$ emission from the operation phase of the building separately. There are relatively few studies in this field that consider spatial correlation, and most studies use non-spatial econometric models for calculation and analysis. In addition, urbanization should be considered from multiple angles to analyze its impact on building $\mathrm{CO}_{2}$ emissions comprehensively.

To fill these gaps, this paper makes a focus on the operation phase of $\mathrm{CO}_{2}$ emissions from urban buildings. The contributions are listed below: first, this paper analyzes the effect of comprehensive urbanization on $\mathrm{CO}_{2}$ emissions from the operation phase of urban civil buildings, while most of the precious articles study the entire life cycle of buildings (Hou et al. 2021, Su et al. 2021, Zhang et al. 2019, Zhang et al. 2020). Second, a comprehensive urbanization indicator is constructed based on the urbanization indicators of the four aspects including population, land, economy, and society, which are used to characterize the comprehensive development level of urbanization. Third, the influence of comprehensive 
urbanization on building $\mathrm{CO}_{2}$ emissions is explored by taking spatial correlation into account based on the spatial panel model. Rarely articles have studied the association between $\mathrm{CO}_{2}$ emissions and urban civil buildings using the spatial panel model (He et al. 2020, Huo et al. 2020, Huo et al. 2021, Li et al. 2021, Wang \&Feng 2018).

This paper is structured as follows: Section 2 gives a review of the literature review on urbanization and building carbon emissions. Section 3 introduces the calculation methods of $\mathrm{CO}_{2}$ emissions from the operation phase of urban buildings, as well as the theoretical models and data sources of various variables used in this research. Section 4 presents empirical analysis. Section 5 draws concludes.

\section{Literature review}

In the field of $\mathrm{CO}_{2}$ emissions, there are two main types of research on urbanization. One is to research the effect of urbanization on carbon emissions by taking the ratio of urban population to the total population of the region as an urbanization indicator. (Ding \&Li 2017) uses the LMDI model for calculation and analysis. The study finds that the mechanism of urbanization impact on carbon emissions has significantly regionally heterogeneous. (Bai et al. 2019) uses the fixed-effect two-stage least squares model based on data from four dimensions of urbanization. And the study concludes that urbanization has increased $\mathrm{CO}_{2}$ emissions. (Han et al. 2019) analyzes the factors that influenced the intensity of $\mathrm{CO}_{2}$ emission based on the extended kaya model. The study finds that urbanization and employment rate of urban population are the major influencing factors and have the effect of decreasing the intensity of $\mathrm{CO}_{2}$ emission. (Chen et al. 2019, Liu \&Liu 2019, Muhammad et al. 2020, Wu et al. 2017) and others study the association between urbanization and $\mathrm{CO}_{2}$ emissions regionally and in groups, while considering regional heterogeneity.

The other emphasizes the harmonization of population, economy, society, and ecological environment based on the new urbanization strategy first proposed in Zhejiang Province in 2006 (Lin \&Zhu 2021). The studies characterize urbanization from multiple perspectives, and then study the relationship between it and $\mathrm{CO}_{2}$ emissions.

(Liu et al. 2018) uses the Tobit model to analyze the impact on 10 typical urban agglomerations from the four aspects of urbanization including population, space, industry, and economy. The study finds that the impact of urbanization in different dimensions on different urban agglomerations varies greatly. (Wang et al. 2019) also establishes a comprehensive urbanization indicator system in four aspects to constitute the quality urbanization. And based on the Geographically Weighted Regression Model (GWR), the study finds that the urbanization quality has significant temporal and spatial distribution differences among provinces. (Zhou et al. 2019) uses a spatial agglomeration function, gray correlation model, Kuznets curve model to analyze the economy, population, and spatial urbanization. The study finds that economy urbanization has the most significant impact on $\mathrm{CO}_{2}$ emissions. (Wang \&Zhao 2018) establishes a comprehensive urbanization indicator system from three aspects including population, technology, and industrial institutions. The country is also divided into three zones according to the the level of urbanization transition and studied separately by using a modified STIRPAT model. The study finds that China's urbanization is uneven, and that the dominant industrial structure has different effects on $\mathrm{CO} 2$ emissions. 
As a major sector of consumption of energy, the construction industry has attracted many scholars' attention. The whole life cycle of a building includes the stages of material production, building construction, building operation and building abandonment. (Chang et al. 2019, Fenner et al. 2018, Wu et al. 2019, Xikai et al. 2019, Zhang et al. 2020, Zhao et al. 2019) argue that $\mathrm{CO}_{2}$ emissions from the constructions' operation phase is the largest proportion of the building's entire life cycle. Few scholars study the association of urbanization and $\mathrm{CO}_{2}$ emissions from buildings, especially during the operation phase of buildings.

(Zhang et al. 2021) establishes urbanization indicators from three aspects including population, economic, and technology. And to study the urbanization effects on building $\mathrm{CO} 2$ emissions, taking region-specific heterogeneity into account. (Huo et al. 2020) establishes a comprehensive indicator system of urbanization based on the quantitative and structural dimensions in three dimensions: population, economy, and space. The study uses the STIRPAT model to study the multiple effects of urbanization on $\mathrm{CO}_{2}$ emissions from the urban construction sector. Furthermore, (Huo et al. 2021) also uses a panel threshold regression model to examine the dynamic mechanisms underlying the effects of urbanization on carbon emissions from urban civil buildings. (Wang et al. 2019) uses a Geographically Weighted Regression model to examine the association of urbanization with carbon emissions in six sectors, including the construction sector. (Liu et al. 2020) uses the system dynamics model to predict the long-run carbon emissions from buildings. And simulates the impact of different policies on the $\mathrm{CO}_{2}$ emissions from buildings in Beijing. The study explains in more detail the urban building stock evolution and reveals the effects of the policies.

In summary, the construction operation stage is considered as the largest carbon emissions in the buildings industry by many studies. However, few studies conduct the effect of urbanization on building $\mathrm{CO}_{2}$ emissions at this stage. To fill the gaps in this research field, this paper conducts further research on it. It mainly reflects in two aspects: (1) To measure urbanization comprehensively, a comprehensive urbanization index is constructed based on the urbanization evaluation system from the four aspects including economy, population, land, and society. (2) In taking the spatial correlation and spatial spillover effects into account, a spatial panel model is applied for the exploration on the effect of urbanization to carbon emissions from the operation phase of urban buildings.

\section{Method and data}

\subsection{Model specifications}

According to the "First Law of Geography", the variables are not independent of each other in the study of the dimensionality of China's provinces but have extensive connections. Considering this connection, the analysis of the problem can be more accurate. Therefore, this paper intends to analyze the effect of urbanization on $\mathbf{C O}_{2}$ emissions from the operation of urban civil buildings (ubec) by using a spatial panel model. 


\subsubsection{Spatial correlation}

Having spatial correlation is the prerequisite for applying spatial econometrics. The measure of spatial self-correlation is divided into global and local statistics. Global autocorrelation statistics are quantitative indicators that reflect whether there is spatial autocorrelation for all provinces, while local autocorrelation statistics are quantitative indicators that reflect whether there is spatial autocorrelation among other surrounding provinces for one province. (Tiyan \&Hanchen 2010). This paper uses the global and local Moran index to test the spatial autocorrelation of $\boldsymbol{u b e c}$. The calculation method is as follows:

Global Moran's I:

$$
I=\frac{n}{\sum_{i} \sum_{j} w_{i j}} \frac{\sum_{i} \sum_{j} w_{i j}\left(x_{i}-\bar{x}\right)\left(x_{j}-\bar{x}\right)}{\sum_{i}\left(x_{i}-\bar{x}\right)^{2}}
$$

Where $n$ represents 30 provinces, $w_{i j}$ is the spatial weight matrix (for measuring the spatial distance between two regions), $x_{i}$ and $x_{j}$ are the independent variables respectively, and $\bar{x}$ are the average values of the independent variables.

The range of Moran's $I$ is $(-1,1)$. $(0,1)$ means positive autocorrelation, while $(-1,0)$ is the opposite. The Moran's $I$ is close to 0 , indicating that the distribution in space is random and there is no spatial autocorrelation.

Local Moran's I:

$$
I=\frac{n\left(x_{i}-\bar{x}\right) \sum_{j \neq i} w_{i j}\left(x_{j}-\bar{x}\right)}{\sum_{i}\left(x_{i}-\bar{x}\right)^{2}}
$$

The meaning of Local Moran's $I$ is similar to Global Moran's $I$. Positive $I_{i}$ means that the high (low) value of area $i$ is surrounded by surrounding high (low) areas; Negative $I_{i}$ means that the high (low) value of area $i$ is surrounded by surrounding low (high) areas(Qiang 2014).

\subsubsection{Spatial panel model}

The general form of the spatial panel model is as follows:

$$
\begin{aligned}
& y_{i t}=\tau y_{i, t-1}+\delta w_{i}^{\prime} y_{t}+x_{i t}^{\prime} \beta+w_{i}^{\prime} X_{t} \theta+u_{i}+\lambda_{t}+\varepsilon_{i t} \\
& \varepsilon_{i t}=\lambda m_{i}^{\prime} \varepsilon_{t}+v_{i t}
\end{aligned}
$$

Among them, $y_{i, t-1}$ is the first-order lag of the explained variable $y_{i t} ; w_{i} x_{t} \theta$ is the spatial lag of the explanatory variable; $\gamma_{r}$ is the time effect; And $m_{i}$ is the $i$ - th row of the disturbance term spatial weight matrix $\mathrm{M}, w_{i j}$ represents an $n \times n$ spatial weight matrix, which measures the spatial distance between regions.

Spatial econometric models allow for three kinds of interactions. One is the interaction of the endogenous dependent variables with each other. Another is the interaction that occurs with exogenous independent variables. And the third one 
is the interaction between disturbance terms ( $\mathrm{Li} \& \mathrm{Li}$ 2020). Therefore, different interaction effects refer to three spatial econometric models.

(1) If $\lambda=0$, it is a Spatial Dubin Model (SDM);

(2) If $\lambda=0$ and $\delta=0$, it is a Spatial Autoregressive Model (SAR);

(3) If $\tau=0$ and $\delta=0$, it is a Spatial Autocorrelation Model (SAC);

(4) If $\tau=\rho=0$ and $\delta=0$, it is a Spatial Error Model (SEM).

In this study, after a series of spatial model tests, the Spatial Dubin Model is finally selected to calculate and explain the impact of urbanization on $\boldsymbol{u b e c}$.

(Liu \&Liu 2019) illustrate the spatial spillover effect mechanism. The Spatial Durbin Model is calculated as follows:

$$
\begin{aligned}
& \left(I_{n}-\rho W\right) y=X \beta+W X \theta_{n}+l_{n} \alpha+\varepsilon \\
& y=\sum_{r=1}^{k} S_{r}(W) x_{r}+V(W)_{t_{r}}+V(W)_{c} \\
& S_{i}(W)=V(W)\left(I_{n} \beta_{r}+W \theta_{r}\right) \\
& V(W)=\left(I_{n}-\rho W\right)^{-1}=I_{n}+\rho W+\rho^{2} W^{2}+\rho^{3} W^{3}+\mathrm{L}
\end{aligned}
$$

Because the effect of explanatory variable varies across region. The total effect means the row (column) mean of the coefficient matrix of the explanatory variable. The direct effect refers to the diagonal mean of the coefficient matrix of the explanatory variable. The indirect effect is the difference between the total and direct effect (LeSage \&Pace 2014).

The spatial weight matrix selected is the spatial inverse distance matrix (take the reciprocal of the distance between regions) in this paper, and records the distance between region $i$ and region $j$ as $d_{i j}$, which can be expressed as:

$$
w_{i j}=\frac{1}{d_{i j}}
$$

The establishment of the Spatial Dubin Model (SDM) is as follows:

$$
\ln u b e c_{i t}=\delta \sum_{j=1}^{30} w_{i j} \ln u b e c_{i t}+\alpha+\beta[u r b, \ln f d i, p u e i]+\sum_{j=1}^{30} w_{i j}[u r b, \ln f d i, p u e i] \theta+u_{i}+\lambda_{t}+\varepsilon_{i t}
$$

Where, ubec means $\mathrm{CO}_{2}$ emissions from the operation phase of urban civil buildings (ten thousand tons); urb means comprehensive urbanization; $f d i$ means foreign direct investment (100 million yuan); puei means energy consumption per capita (ten thousand tons of standard coal per person); $\varepsilon_{i t}$ means disturbance term. 


\subsubsection{Calculation of and ubec}

According to the "Professional Knowledge of Housing Construction Engineering" and the "Regulations on Energy Conservation of Civil Buildings", according to the nature of using, buildings are classified into civil buildings, industrial buildings, and agricultural buildings. Civil buildings are divided into residential and public buildings (Mengjie 2019). The energy consumption of civil buildings is classified into urban, rural and northern heating energy consumption. Generalized building energy consumption is usually measured as the whole life cycle of the building, while it refers to the energy consumption from the operation phase of the building in the narrow sense. In 2000, the Ministry of Construction formally unified the definition of building energy consumption. And defined building energy consumption as energy consumption from the operation phase of building (Jia 2016). The scope of this paper is the operational phase of urban civil buildings. Energy consumption and $\mathrm{CO}_{2}$ emissions are calculated at this stage, and heating energy consumption in the north is not calculated separately.

$$
\text { ubec }=\sum\left(\mathrm{e}_{j} \times \delta_{j} \times \varepsilon_{j}\right)
$$

Where:

ubec - Total $\mathrm{CO}_{2}$ emissions from the operation phase of urban civil buildings;

$e_{j}$ - The energy consumption of urban civil buildings in the energy balance sheet (physical quantity);

$\delta_{j} \longrightarrow$ The heat conversion factor;

$\varepsilon_{j} \ldots$ The j-th energy $\mathrm{CO}_{2}$ emission coefficient of urban civil buildings.

In energy statistics, there are no statistics on energy consumption from the operation phase of buildings. In terms of the energy consumption characteristics of each industry, the energy consumption of wholesale, retail and accommodation, catering, other tertiary industries, and living consumption after deducting transportation energy consumption mainly occur in the operation phase of buildings. It can be used as the energy consumption of the building (Min et al. 2012).

The average low calorific value uses the data from the appendix of the "China Energy Statistical Yearbook". The $\mathrm{CO}_{2}$ emission coefficient is the data given in the 2006 edition of the "IPCC National Greenhouse Gas Inventory Compilation Guidelines". As shown in Table 1:

Table 1 Average lower heating value and $\mathrm{CO}_{2}$ emission coefficient

\begin{tabular}{ccc|ccc}
\hline Energy & $\begin{array}{c}\text { Average lower } \\
\text { heating value } \\
\left(\mathrm{kcal} / \mathrm{kg}\left(\mathrm{m}^{3}\right)\right)\end{array}$ & $\begin{array}{c}\mathrm{CO}_{2} \text { emission } \\
\text { coefficient } \\
\left(\mathrm{kgCO}_{2} / \mathrm{TJ}\right)\end{array}$ & Energy & $\begin{array}{c}\text { Average lower } \\
\text { heating value } \\
\left(\mathrm{kcal} / \mathrm{kg}\left(\mathrm{m}^{3}\right)\right)\end{array}$ & $\begin{array}{c}\mathrm{CO}_{2} \text { emission } \\
\text { coefficient } \\
\left(\mathrm{kgCO}_{2} / \mathrm{TJ}\right)\end{array}$ \\
\hline Raw coal & 5000 & 97500 & Diesel oil & 10200 & 74100 \\
\hline Washed coal & 6300 & 94600 & Fuel oil & 10000 & 77400 \\
\hline Mould coal & 4200 & 97500 & LPG & 12000 & 63100
\end{tabular}




\begin{tabular}{cccccc}
\hline Coke Oven Gas & 4200 & 44400 & Natural gas & 9310 & 56100 \\
\hline Gasoline & 10300 & 69300 & & \\
\hline
\end{tabular}

\subsubsection{Establishment of a comprehensive index system for urbanization}
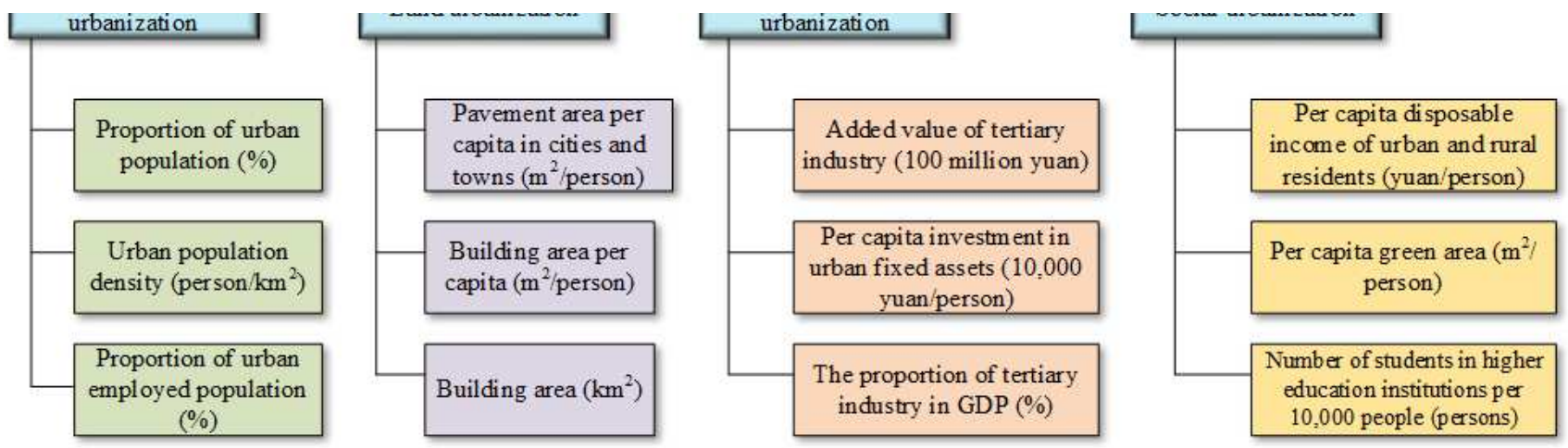

Figure 1.
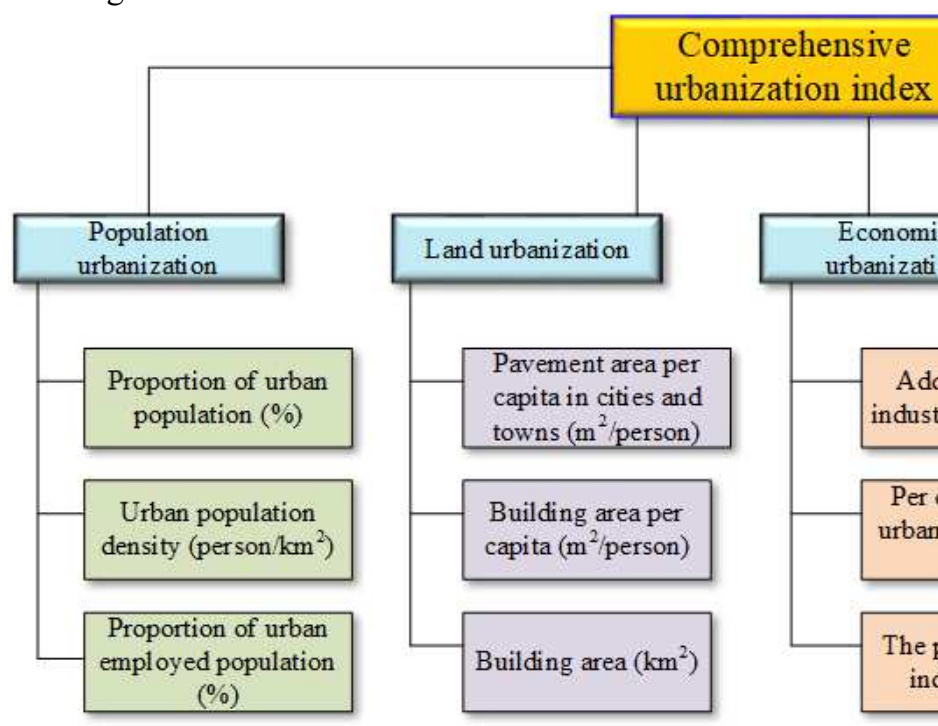

Figure 1 Comprehensive index system of urbanization

The entropy method avoids errors caused by the subjective preference of experts in the subjective weighting method.

This method was introduced by Shannon in 1948 to the discipline of information management to express information or uncertainty (Shen et al. 2015). In this paper, this method is used to objectively weigh the indicators mentioned in the previous chapter to obtain a new comprehensive urbanization index to measure the development of China's urbanization process, and then to study its impact on $\boldsymbol{u b e c}$. The main entropy method's calculation steps are as follows: $j=1, \ldots \ldots, n)$. Because the measurement units of each indicator are not standardized, they need to be standardized before calculating the comprehensive urbanization indicator. Processing methods for positive indicators and negative indicators are different, and the formula is as follows: 
Positive indicators:

$$
x_{i j}^{\prime}=\frac{x_{i j}-\min \left\{x_{1 j}, \mathrm{~K}, x_{n j}\right\}}{\max \left\{x_{1 j}, \mathrm{~K}, x_{n j}\right\}-\min \left\{x_{1 j}, \mathrm{~K}, x_{n j}\right\}}
$$

Negative indicators:

$$
x_{i j}=\frac{\max \left\{x_{1 j}, \mathrm{~K}, x_{n j}\right\}-x_{i j}}{\max \left\{x_{1 j}, \mathrm{~K}, x_{n j}\right\}-\min \left\{x_{1 j}, \mathrm{~K}, x_{n j}\right\}}
$$

(2) Calculate the weight of the $i$-th sample value under the $j$-th index in the index:

$$
p_{i j}=\frac{x_{i j}^{\prime}}{\sum_{i=1}^{n} x_{i j}^{\prime}}
$$

(3) Calculate the entropy value of the $j$-th index:

Where, $k=1 / \ln (n)>0, \mathrm{e}_{j} \geq 0$.

(4) Calculate information entropy redundancy (difference):

$$
d_{j}=1-e_{j}, j=1, \mathrm{~K}, m
$$

(5) Calculate the weight of each indicator:

$$
w_{j}=\frac{d_{j}}{\sum_{j=1}^{m} d_{j}}, j=1, \mathrm{~L}, m
$$

(6) Calculate the comprehensive score of each sample:

$$
s_{i}=\sum_{j=1}^{m} w_{j} x_{i j}^{\prime}, i=1, \mathrm{~L}, n
$$

\begin{tabular}{|c|c|c|c|c|c|c|}
\hline & classification & variables & $\begin{array}{l}\text { Positive } \\
\text { negative }\end{array}$ & 1 & Weights & $\begin{array}{l}\text { overall } \\
\text { ratings }\end{array}$ \\
\hline \multirow{4}{*}{$\begin{array}{l}\text { Comprehensive } \\
\text { urbanization }\end{array}$} & \multirow{3}{*}{$\begin{array}{l}\text { Population } \\
\text { urbanization }\end{array}$} & Proportion of urban population & - & & 0.037 & 0.002 \\
\hline & & Urban population density & - & & 0.036 & 0.036 \\
\hline & & $\begin{array}{l}\text { Proportion of employed population } \\
\text { in urban }\end{array}$ & + & & 0.043 & 0.000 \\
\hline & Land & Pavement area per capita in urban & + & & 0.073 & 0.147 \\
\hline
\end{tabular}

For weights and a comprehensive score of the provincial indicators in the comprehensive urbanization indicator system, this paper uses Beijing in 2017 as an example. The result is shown in Table 2Table 2.

Table 2 Comprehensive urbanization indicator system of Beijing in 2017 


\begin{tabular}{|c|c|c|c|c|}
\hline \multirow[t]{2}{*}{ urbanization } & Building area per capita & + & 0.080 & 0.027 \\
\hline & Construction area & + & 0.098 & 0.018 \\
\hline \multirow{3}{*}{$\begin{array}{l}\text { Economy } \\
\text { urbanization }\end{array}$} & Added value of tertiary industry & + & 0.118 & 0.051 \\
\hline & $\begin{array}{l}\text { Per capita investment in urban fixed } \\
\text { assets }\end{array}$ & + & 0.043 & 0.010 \\
\hline & $\begin{array}{l}\text { The proportion of tertiary industry in } \\
\text { GDP }\end{array}$ & + & 0.128 & 0.128 \\
\hline \multirow{3}{*}{$\begin{array}{l}\text { Society } \\
\text { urbanization }\end{array}$} & $\begin{array}{l}\text { Per capita disposable income of } \\
\text { urban and rural residents }\end{array}$ & + & 0.183 & 0.182 \\
\hline & Green area per capita & + & 0.106 & 0.057 \\
\hline & $\begin{array}{l}\text { Number of students in high schools } \\
\text { per } 10,000 \text { people }\end{array}$ & + & 0.055 & 0.055 \\
\hline
\end{tabular}

\subsubsection{Other indicator data}

This study uses panel data from 30 provinces for 10 years from 2008 to 2017. Due to the unavailability and accuracy of the data, Tibet, Hong Kong, Macao, and Taiwan are not included. The $\boldsymbol{u b e c}$ is calculated based on the data of the "China Energy Statistical Yearbook", and the data for other variables are from the "China Statistical Yearbook". To avoid errors caused by inflation and other reasons, the added value of the tertiary industry is calculated at comparable prices in 2008 .

\section{Results and discussion}

\subsection{Analysis of calculation results of $u b e c$}

According to the calculation method, the $\boldsymbol{u b e c}$ emissions can be obtained. The overall change trend of $\boldsymbol{u b e c}$ is shown

280 in Figure 2. In the past 10 years, ubec shows an overall increasing trend, and the growth rate has begun to decline after 281 2011. Since 2014, the growth rate has been increasing again. In 2017, ubec was 104,822×104 t, an increase of 7.3\% over 2822016.

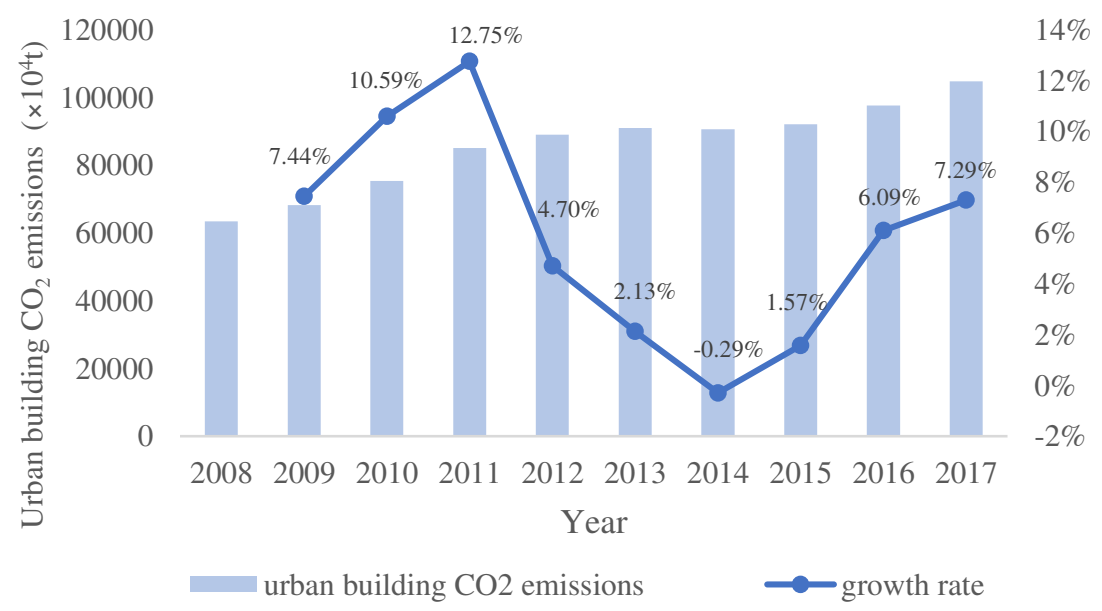

Figure 2 The trend of $\boldsymbol{u b e c}$

To analyze the spatial movement of China's building carbon emissions in recent years, this study uses ArcGIS 10.2 to draw the center of gravity of $\boldsymbol{u b e c}$. When the carbon emission center shifts to a certain direction, it means that the spatial 
distribution of regional carbon emission is uneven during this period (Yuewu et al. 2016). It can be seen from Figure 3 that from 2008 to 2017, the center of gravity of $\boldsymbol{u b e c}$ across the country has not moved much, but it mainly concentrates in Henan Province, and the overall trend is moving from the northeast to the northwest. This shows that the $\boldsymbol{u b e c}$ has obvious spatial and regional ineven characteristics, and further confirms the necessity of studying carbon emissions from a spatial perspective.

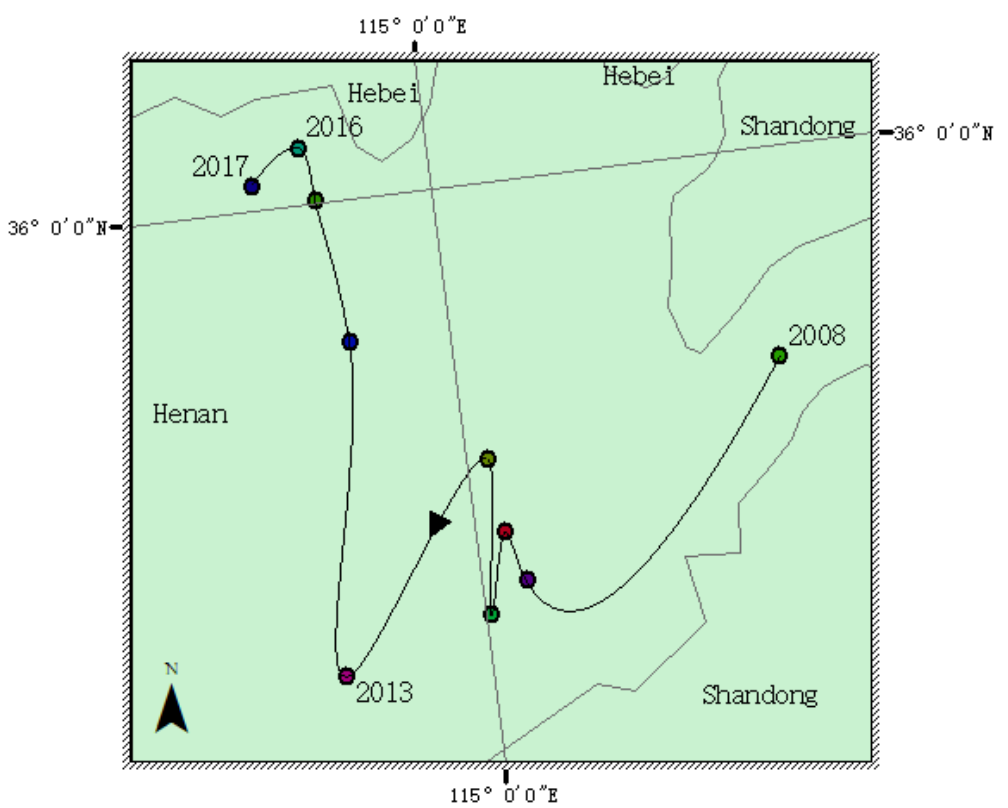

Figure 3 Variations in center of gravity for $\mathrm{CO}_{2}$ concentration

\subsection{Spatial distribution of comprehensive urbanization}

The comprehensive urbanization is an indicator for comprehensively measuring the process of China's urbanization.

Figure 4 shows the development process of comprehensive urbanization in 30 provinces of China. It can be concluded that provinces with high urbanization in the early stage were mainly in the eastern coastal region, and they gradually transferred of China's economy, society, land, and many other aspects.
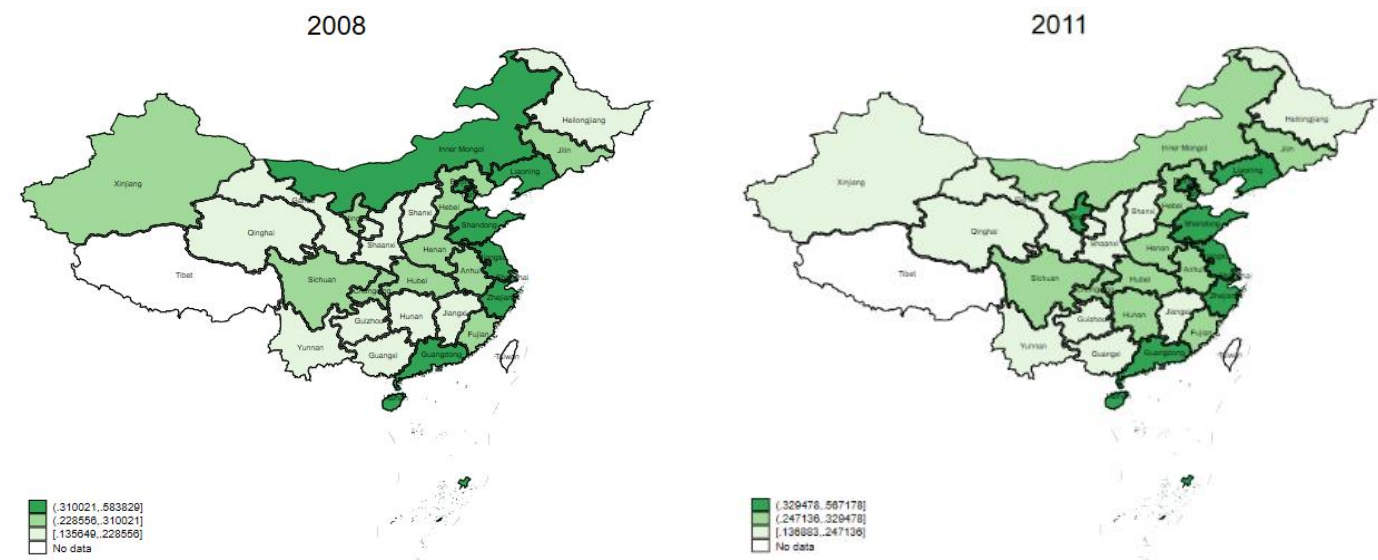

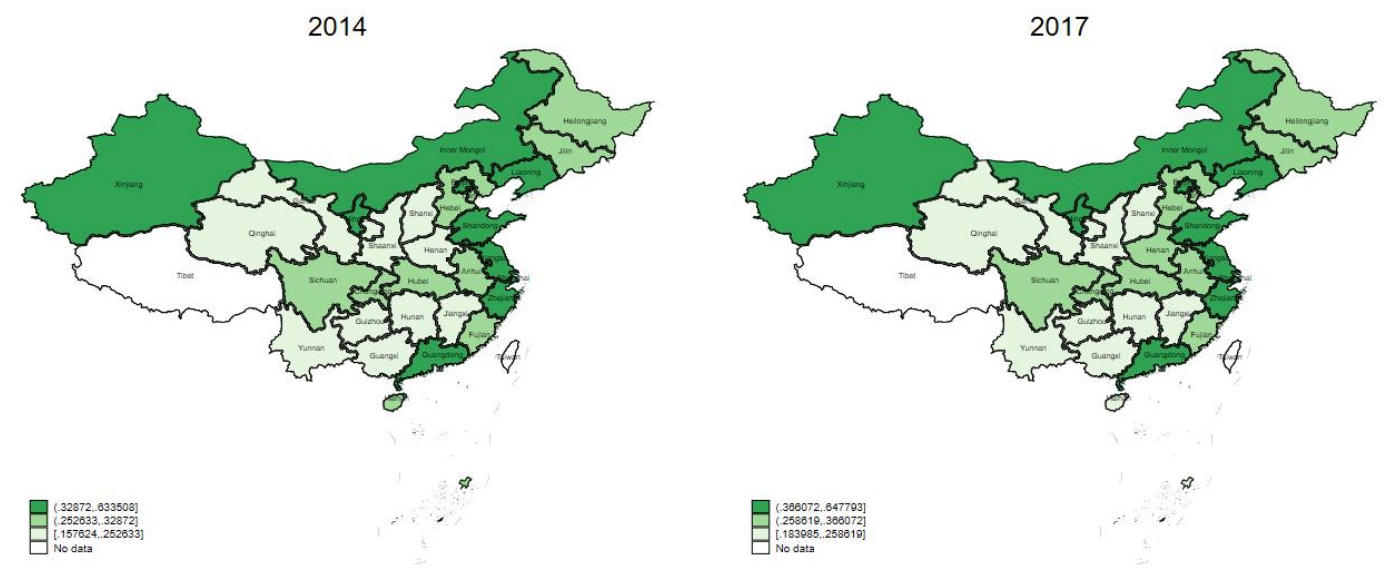

Figure 4 Spatial distribution maps of comprehensive urbanization

\section{$300 \quad$ 4.3 Spatial correlation analysis}

Global Moran's I are listed in Table 3. The Moran's I are all positive and almost greater than 0.2, which is significant at $1 \%$ level. It suggests that $\boldsymbol{u b e c}$ has positive spatial effect.

Table 3 Global Moran's I

\begin{tabular}{llll}
\hline Year & $\mathbf{I}$ & $\mathbf{Z}$ & P-value \\
\hline 2008 & 0.301 & 4.243 & 0.0001 \\
2009 & 0.282 & 4.005 & 0.0001 \\
2010 & 0.279 & 3.957 & 0.0001 \\
2011 & 0.247 & 3.558 & 0.0001 \\
2012 & 0.242 & 3.504 & 0.0001 \\
2013 & 0.236 & 3.415 & 0.0010 \\
2014 & 0.241 & 3.486 & 0.0001 \\
2015 & 0.239 & 3.453 & 0.0010 \\
2016 & 0.213 & 3.123 & 0.0020 \\
2017 & 0.195 & 2.907 & 0.0040 \\
\hline
\end{tabular}


As shown in Figure 5, most provinces in China are distributed in one and three quadrants, which further proves the positive spatial effect of $\boldsymbol{u b e c}$ among provinces in China.
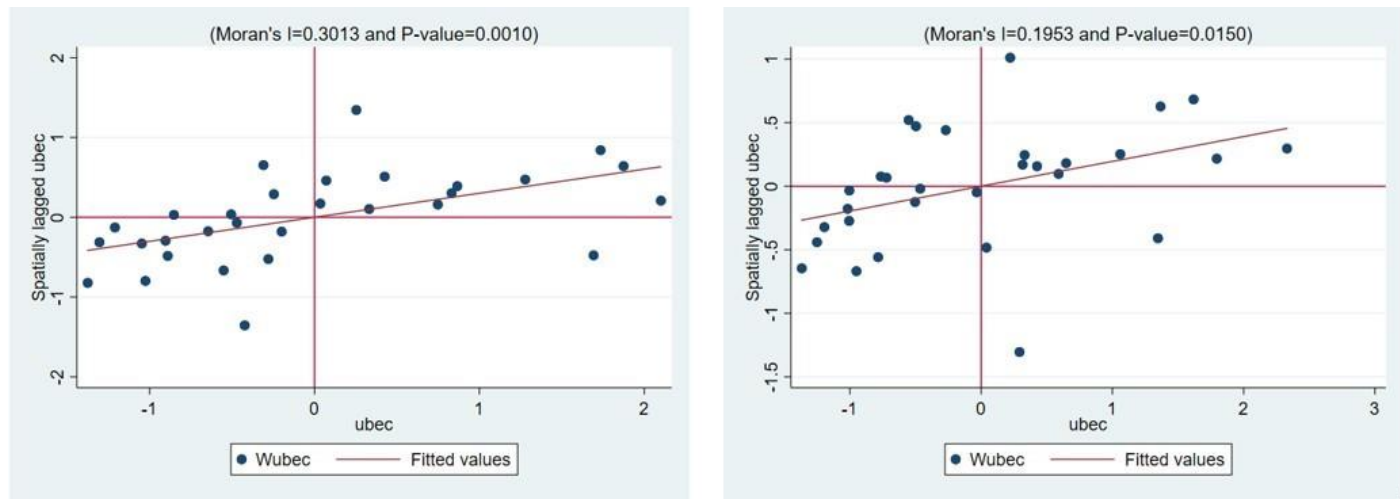

Figure 5 2008(left) and 2017(right) Moran scatter plots

Since the Moran scatter plots can't judge the statistical significance of clustering. And additional analysis using LISA is necessary $(\mathrm{Li} \& \mathrm{Li} 2020)$.

Figure 6 shows the LISA and salience graphs used to examine the local autocorrelation of ubec in 2008. In H-H type provinces, Beijing, Shanghai, and Jilin are significant at 1\% level. Jiangsu, Inner Mongolia, and Hebei are significant at 5\% level and Liaoning is significant at $0.1 \%$ level. In H-L type provinces, Guangdong is significant at $5 \%$ level. In L-H provinces, Tianjin is significant at 5\% level. In L-L type provinces, Sichuan, and Guizhou are significant at 1\% level, while Xinjiang, Gansu, Qinghai, Chongqing, Guangxi, and Hainan are significant at 5\% level.

Figure 7 shows the LISA and salience graphs used to examine the local autocorrelation of $\boldsymbol{u b e c}$ in 2017. In the H-H type provinces, Jilin and Hebei are significant at the level of 5\%, and Liaoning is significant at the level of $0.1 \%$. In the $\mathrm{H}$ L type provinces, Xinjiang is significant at $0.1 \%$ level, and Guizhou is significant at $5 \%$ level. Compared with 2008, Beijing and Shanghai are move to the L-H type provinces. In L-L type provinces, Sichuan is significant at $1 \%$ level, Hainan, Guangxi and Gansu are significant at 5\% level.

Through comparative analysis, we can see that high emission concentration areas mainly concentrated in highly developed areas and the northern provinces in 2008. The northern provinces, including the old industrial bases in the northeast, are mostly heavy industries and lack innovation in the treatment of carbon emission pollution. The population density in highly developed areas was relatively high. China was in the stage of high-speed economic development at that time, and people's environmental protection consciousness was not strong. With the strengthening of China's strength in various fields, the gradually increase in people's awareness of environmental protection, and the implementation of policies such as the great development of the western part of the country, the growth of carbon emissions has slowed down significantly by 2018 . The high emission concentration area gradually shifts to the western region. 

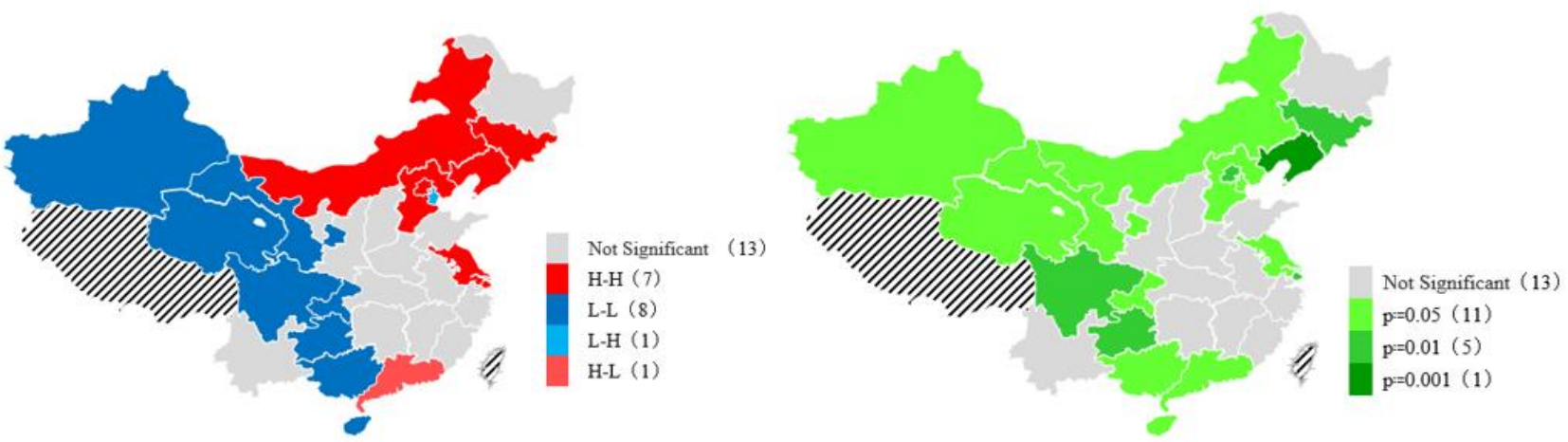

Figure 6 LISA and significance of $\mathrm{CO}_{2}$ emissions in 2008
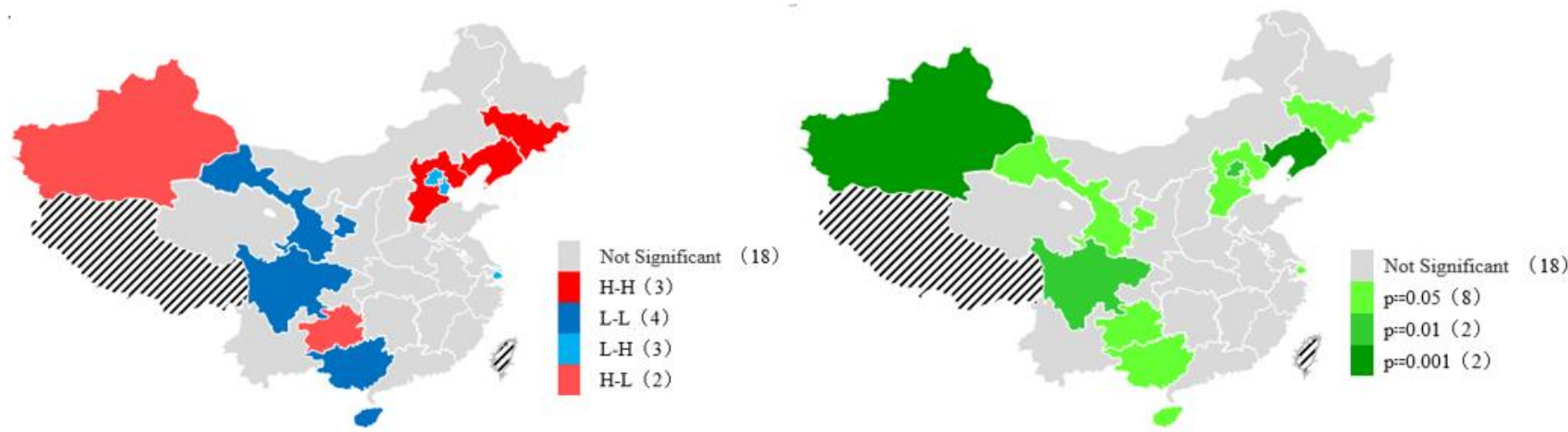

Figure $7 \mathrm{CO}_{2}$ emissions in 2017 LISA diagrams and significance

\subsection{Spatial model diagnosis and Spatial Dubin Model estimation}

\subsubsection{Spatial model diagnostics}

The previous article verifies that the positive spatial correlation of $\boldsymbol{u b e c}$ among Chinese provinces. It shows that a spatial panel model needs to use, but some tests are required to complete the selection of which spatial panel model to use.

\section{Hausman test}

First, the Hausman test is used to choose whether to use a fixed or random effect. The statistical value is 22.95 and the p-value is 0.00001 . The original hypothesis is rejected at $1 \%$ significance level, so the former should be chosen.

To test which of the three effects of regional fixed effect, time, and double fixed effect is the most appropriate for the study in this paper, the effect test is carried out. From the results, regional and double fixed effects' p-value is 0.0508 , and the null hypothesis is not rejected at the $5 \%$ significance level. For the test of time double fixed effects, the p-value is 0.00001 , rejecting the null hypothesis at the $1 \%$ significance level. It is more appropriate to choose a regional fixed-effect model.

\section{2. $\quad$ LM Test, Wald Test and LR Test}

Based on the results in Table 4, for the LM test, the P values of LM - error and LM - lag are significant, rejecting the non-spatial hypothesis. For the Wald test, the P values of Wald - SAR and Wald - SEM are both significant at the 1\% level, 
rejecting the hypothesis that SDM can degenerate into SAR model or SEM model. The LR test results are consistent with the Wald test results.

Table 4 shows the test results. To sum up, this study uses the Spatial Dubin Model (SDM).

Table 4 Test results

\begin{tabular}{cc}
\hline Tests & Results \\
\hline LM - error & $28.634^{* * *}$ \\
LM - lag & $3.89^{* *}$ \\
Wald Test for SAR & $32.74^{* * *}$ \\
Wald Test for SEM & $28.44^{* * *}$ \\
LR test for SAR & $31.10^{* * *}$ \\
LR test for SEM & $27.94^{* * *}$ \\
\hline
\end{tabular}

***, **, * represent significant at $1 \%, 5 \%$ and $10 \%$, respectively.

\subsubsection{Spatial Dubin model estimation}

The Spatial Dubin Model reflects the impact of comprehensive urbanization (urb), foreign direct investment $(\boldsymbol{f d i})$ and per capita energy consumption (uei). And it also reflects the spatial spillover effect of the above indicators on ubec

After the previous analysis, this study finally selected the regional fixed-effect spatial Dubin model, and used stata15.0 to complete the calculation and analysis. The estimated results are shown in Table 5.

Table 5 Estimated results

\begin{tabular}{|c|c|c|c|}
\hline Variables & Spatial fixed effects & Variables & Spatial fixed effects \\
\hline urb & $\begin{array}{c}-0.890^{* * *} \\
(0.275)\end{array}$ & W*puei & $\begin{array}{c}-0.228 \\
(0.309) \\
\end{array}$ \\
\hline Infdi & $\begin{array}{l}0.027^{*} \\
(0.015)\end{array}$ & W*Inubec & $\begin{array}{c}0.364 * * * \\
(0.309)\end{array}$ \\
\hline puei & $\begin{array}{c}1.344 * * * \\
(0.071)\end{array}$ & $\mathbf{R}^{2}$ & 0.7674 \\
\hline$W^{*}$ urb & $\begin{array}{c}4.091 * * * \\
(0.694)\end{array}$ & $\delta^{2}$ & 0.0092 \\
\hline$W * \operatorname{lnfdi}$ & $\begin{array}{c}0.063 * * * \\
(0.023)\end{array}$ & Log-likelihood & 275.55 \\
\hline
\end{tabular}

***, ${ }^{* *}, *$ represent significant at $1 \%, 5 \%$ and $10 \%$, respectively.

The spatial autoregressive coefficient is positive and significant at the $1 \%$ level. It means that the ubec has positive spatial spillover effect. That is, every increase of one unit of ubec in neighboring areas will increase the area's carbon emissions by $0.364 \%$.

Comprehensive urbanization (urb) is significant at the $1 \%$ level and effectively suppresses the increase in $\boldsymbol{u b e c}$. Based on the data, $1 \%$ increase of local comprehensive urbanization, will reduce $0.89 \%$ of the $\boldsymbol{u b e c}$. However, the increase in comprehensive urbanization in neighboring areas has contributed significantly to local carbon emissions. $1 \%$ increase in 
comprehensive urbanization in neighboring areas, will increase $4.091 \%$ of the $\boldsymbol{u b e c}$. This result shows that while developing comprehensive urbanization, more attention should be paid to avoiding carbon transfer between provinces.

Foreign direct investment $(\boldsymbol{f d i})$ has a promoting effect on the $\boldsymbol{u b e c}$, and it is significant at the $10 \%$ level. $1 \%$ increase

\subsection{Estimation and analysis of spatial spillover effects}

in local foreign direct investment, will increase $0.027 \%$ of the carbon emissions of local urban civil buildings. $f d i$ in neighboring regions also promotes local carbon emissions. The results show that $\mathrm{f} f \boldsymbol{d i}$ drives China's economic development, and it also drives the increase in $\boldsymbol{u b e c}$.

Per capita energy consumption (puei) also promotes the ubec, and it is significant at the $1 \%$ level. $1 \%$ increase in local energy consumption per capita, will increase $1.344 \%$ of the $\mathrm{CO}_{2}$ emissions of local urban civil building. The puei of neighboring areas has no significant effect on local $\mathrm{CO}_{2}$ emissions, but its coefficient is positive, which also has a promoting effect to some extent. This result shows that puei plays a leading role in increasing $\boldsymbol{u b e c}$. It can be said that reducing puei is an effective way to reduce emissions.

Considering that there may exist deviations to test spillover effect by using point estimation. The direct,indirect, and total effects of ubec are estimated by using the partial differential method in this section ( $\mathrm{Li}$ et al. 2019). The estimated results are shown in Table 6.

Table 6 Test results of space spillover effect (Spatial fixed effects)

\begin{tabular}{cccc}
\hline Variables & Total effects & Direct effects & Indirect effects \\
\hline \multirow{2}{*}{ urb } & $5.028199^{* * *}$ & $-0.6985205^{* *}$ & $5.72672^{* * *}$ \\
& $(0.9635)$ & $(0.2742)$ & $(0.9611)$ \\
\hline \multirow{2}{*}{$\boldsymbol{\text { nfdi }}$} & $0.1409718^{* * *}$ & $0.02972^{* *}$ & $0.1112517^{* * *}$ \\
& $(0.0373)$ & $(0.0143)$ & $(0.0331)$ \\
\hline \multirow{2}{*}{$\boldsymbol{p u e i}$} & $1.757843^{* * *}$ & $1.36298^{* * *}$ & 0.394863 \\
& $(0.3471)$ & $(0.0682)$ & $(0.3355)$ \\
\hline
\end{tabular}

***, $* *, *$ represent significant at $1 \%, 5 \%$ and $10 \%$, respectively.

It can be seen from Table 6 that the estimated results of the direct, indirect, and total effects of comprehensive urbanization are $-0.7,5.73$ and 5.03 , respectively. For the direct effect, $1 \%$ increase in comprehensive urbanization will reduce the carbon emissions of urban civil buildings by $0.7 \%$. It means that the level of local comprehensive urbanization will increase, because of the changes in urban population, land use structure, tertiary industry, the development of economy, the improvement of education level and the living standard of residents, which will restrain the increase of $\boldsymbol{u b e c}$. However, the indirect effects show positive impacts. $1 \%$ increase in the comprehensive urbanization of neighboring areas, will increase $5.73 \%$ of the $\boldsymbol{u b e c}$ in local cities and towns. The main reason is that with the vigorous implementation of environmental protection policies, the growth of comprehensive urbanization in neighboring areas has caused the shift of some industries with high carbon emissions and increased the $\boldsymbol{u b e c}$ in local cities and towns. The total effect obtained by adding the direct and indirect effects is positive. So comprehensive urbanization has a significant role in promoting $\boldsymbol{u b e c}$.

The estimated results of the direct effect, indirect effect and total effect of $f d i$ are $0.03,0.11$ and 0.14 , respectively. In this article, $\boldsymbol{f d i}$ is used to express the degree of trade openness. The impact of trade openness on our country mainly has 
two aspects. On the one hand, foreign investment can bring advanced technology to developing countries and make them develop rapidly in line with the trend. On the other hand, the effect is the opposite. To attract foreign investment, developing countries lower the standards of environmental regulations, which may make them become "pollution haven" for developed countries (Chen et al. 2020). Regardless of direct effect, indirect effect or total effect, foreign direct investment can promote carbon emissions from urban civil buildings. Specifically speaking from the perspective of the overall effect, $1 \%$ increase in foreign direct investment will increase the carbon emissions of urban civil buildings by $0.14 \%$. In other words, the influence of foreign capital on my country is more inclined to the second aspect.

The direct effect, indirect effect and total effect of per capita energy consumption are estimated to be 1.36, 0.39 and 1.75 respectively. From the perspective of the overall effect, every $1 \%$ increase in per capita energy consumption will increase the carbon emissions of urban civil buildings by $1.75 \%$. There are two main reasons. On the one hand, our country uses a single energy structure. For example, heating and industrial production in northern are dominated by coal. The combustion of coal will produce a large amount of $\mathrm{CO}_{2}$, which will have extremely adverse effects on the environment. On the other hand, China's energy utilization rate is low, and the rapid development of the economy is at the expense of energy use.

\section{Conclusion}

This study uses the entropy method to construct an indicator that aims to comprehensively describe China's urbanization process -- comprehensive urbanization in four dimensions including population, economy, land, and society urbanization. By combining the characteristics of geographical space distribution, and considering the spatial correlation and spatial spillover effects, this paper comprehensively analyzes the effect of comprehensive urbanization on the $\boldsymbol{u b e c}$.

First, the $\boldsymbol{u b e c}$ has obviously positive spillover effects in space. The increase of $\mathrm{CO}_{2}$ emissions from neighboring areas will drive the increase of local $\mathrm{CO}_{2}$ emissions. Therefore, it is essential to take spatial effects into account.

Second, the areas with high comprehensive urbanization are mainly located in the eastern coastal areas. The reason is that the eastern coastal areas are rich in resources and technology advanced. However, with the accelerated development of China, the implementation of national policies, highly comprehensive urbanization is gradually transitioning to the western region. China is showing a good trend of all-round development.

Third, comprehensive urbanization promotes the ubec. This indicates that the development direction of China's promotion of comprehensive urbanization and reduction of the $\boldsymbol{u b e c}$ is inconsistent. Therefore, we cannot blindly pursue urbanization development. We must make practical and reasonable decisions to achieve a win-win goal. For example, planning urban construction area and population rationally, increasing urban green area, and increasing support for clean energy companies.

Fourth, foreign direct investment has increased the ubec. This shows that the government must do a good job of controlling relevant policies to avoid becoming a "pollution paradise" for developed countries. Comprehensively and reasonably allocating foreign capital, to support more investment to be used in clean energy industries but less investment for high-carbon emission industries. 
Finally, energy consumption per capita has significantly increased the ubec, which shows that China needs to vigorously develop high-tech industries and accelerate the development and utilization of clean energy. Adhere to "green development" as the core, and not forget that low-carbon is the prerequisite for all development while developing the economy and other aspects.

This study takes the $\boldsymbol{u b e c}$ in 30 provinces in China except for Tibet, Hong Kong, Macao, and Taiwan in the past 10 years as the research object, and explores the effects of comprehensive urbanization on the ubec from the spatial effect's perspective. It enriches the current research in this field. However, the research scope of this paper is only in the operation phase of urban civil buildings, and carbon emissions in other phases are not considered, and further research is needed.

\section{References:}

Bai Y, Deng X, Gibson J, Zhao Z, Xu H (2019): How does urbanization affect residential CO2 emissions? An analysis on urban agglomerations of China. J CLEAN PROD 209, 876-885

Chang C, Yang C, Lin T (2019): Carbon dioxide emissions evaluations and mitigations in the building and traffic sectors in Taichung metropolitan area, Taiwan. J CLEAN PROD 230, 1241-1255

Chen J, Wang L, Li Y (2020): Research on the impact of multi-dimensional urbanization on China's carbon emissions under the background of COP21. J ENVIRON MANAGE 273, 111123

Chen J, Xu C, Xie Q, Song M (2020): Net primary productivity-based factors of China's carbon intensity: A regional perspective. GROWTH CHANGE 51, 1727-1748

Chen J, Gao M, Mangla SK, Song M, Wen J (2020): Effects of technological changes on China's carbon emissions. TECHNOL FORECAST SOC 153, 119938

Chen S, Jin H, Lu Y (2019): Impact of urbanization on CO2 emissions and energy consumption structure: A panel data analysis for Chinese prefecture-level cities. STRUCT CHANGE ECON D 49, 107-119

Ding Y, Li F (2017): Examining the effects of urbanization and industrialization on carbon dioxide emission: Evidence from China's provincial regions. ENERGY 125, 533-542

Fenner AE, Kibert CJ, Woo J, Morque S, Razkenari M, Hakim H, Lu X (2018): The carbon footprint of buildings: A review of methodologies and applications. Renewable and Sustainable Energy Reviews 94, 1142-1152

Han X, Cao T, Sun T (2019): Analysis on the variation rule and influencing factors of energy consumption carbon emission intensity in China's urbanization construction. J CLEAN PROD 238, 117958

He J, Yue Q, Li Y, Zhao F, Wang H (2020): Driving force analysis of carbon emissions in China's building industry: 20002015. SUSTAIN CITIES SOC 60, 102268

Hou H, Feng X, Zhang Y, Bai H, Ji Y, Xu H (2021): Energy-related carbon emissions mitigation potential for the construction sector in China. ENVIRON IMPACT ASSES 89, 106599

Huo T, Li X, Cai W, Zuo J, Jia F, Wei H (2020): Exploring the impact of urbanization on urban building carbon emissions in China: Evidence from a provincial panel data model. SUSTAIN CITIES SOC 56, 102068 
Huo T, Cao R, Du H, Zhang J, Cai W, Liu B (2021): Nonlinear influence of urbanization on China's urban residential building carbon emissions: New evidence from panel threshold model. SCI TOTAL ENVIRON 772, 145058 Jia Y (2016): The Difference Research on Energy Consumption and Carbon Emission of Town Civil Building in China's 28 Provinces.

LeSage J, Pace RK (2014): Introduction to Spatial Econometrics. PEKING UNIVERSITY PRESS

Li H, Qiu P, Wu T (2021): The regional disparity of per-capita CO2 emissions in China's building sector: An analysis of macroeconomic drivers and policy implications. ENERG BUILDINGS 244, 111011

Li J, Li S (2020): Energy investment, economic growth and carbon emissions in China-Empirical analysis based on spatial Durbin model. ENERG POLICY 140, 111425

Li L, Hong X, Peng K (2019): A spatial panel analysis of carbon emissions, economic growth and high-technology industry in China. STRUCT CHANGE ECON D 49, 83-92

Lin B, Zhu J (2021): Impact of China's new-type urbanization on energy intensity: A city-level analysis. ENERG ECON 99, 105292

Liu B, Tian C, Li Y, Song H, Ma Z (2018): Research on the effects of urbanization on carbon emissions efficiency of urban agglomerations in China. J CLEAN PROD 197, 1374-1381

Liu F, Liu C (2019): Regional disparity, spatial spillover effects of urbanisation and carbon emissions in China. J CLEAN PROD 241, 118226

Liu P, Lin B, Zhou H, Wu X, Little JC (2020): CO2 emissions from urban buildings at the city scale: System dynamic projections and potential mitigation policies. APPL ENERG 277, 115546

Mengjie W 2019: Study on Regional Differences and Driving Factors of Carbon Emissions in Urban Civil Buildings in China

Min Z, Jing HU, Jie D, Lifeng LI (2012): The Accounting of CO2 Emissions Based on the Energy Balances. Ecological Economy, 30-32,157

Muhammad S, Long X, Salman M, Dauda L (2020): Effect of urbanization and international trade on CO2 emissions across 65 belt and road initiative countries. ENERGY 196, 117102

Pang J, Li N, Mu H, Zhang M (2021): Empirical analysis of the interplay between shadow economy and pollution: With panel data across the provinces of China. J CLEAN PROD 285, 124864

Qiang C (2014): GAOJI JILIANG JINGJIXUE JI STATA YINGYONG

Shen L, Zhou J, Skitmore M, Xia B (2015): Application of a hybrid Entropy-McKinsey Matrix method in evaluating sustainable urbanization: A China case study. CITIES 42, 186-194

Su S, Zhu C, Li X, Wang Q (2021): Dynamic global warming impact assessment integrating temporal variables: Application to a residential building in China. ENVIRON IMPACT ASSES 88, 106568 Tiyan S, Hanchen Y (2010): KONGJIAN JILIANG JINGJIXUE(DI-ER BAN). PEKING UNIVERSITY PRESS

Wang M, Feng C (2018): Exploring the driving forces of energy-related CO2 emissions in China's construction industry 
by utilizing production-theoretical decomposition analysis. J CLEAN PROD 202, 710-719

Wang Y, Zhao T (2018): Impacts of urbanization-related factors on CO 2 emissions: Evidence from China's three regions with varied urbanization levels. ATMOS POLLUT RES 9, 15-26

Wang Y, Li X, Kang Y, Chen W, Zhao M, Li W (2019): Analyzing the impact of urbanization quality on CO2 emissions: What can geographically weighted regression tell us? RENEW SUST ENERG REV 104, 127-136

Wang Y, Luo X, Chen W, Zhao M, Wang B (2019): Exploring the spatial effect of urbanization on multi-sectoral CO2 emissions in China. ATMOS POLLUT RES 10, 1610-1620

Wu P, Song Y, Zhu J, Chang R (2019): Analyzing the influence factors of the carbon emissions from China's building and construction industry from 2000 to 2015. J CLEAN PROD 221, 552-566

Wu Y, Shen J, Zhang X, Skitmore M, Lu W (2017): Reprint of: The impact of urbanization on carbon emissions in developing countries: a Chinese study based on the U-Kaya method. J CLEAN PROD 163, S284-S298

Wu Y, Wang P, Liu X, Chen J, Song M (2020): Analysis of regional carbon allocation and carbon trading based on net primary productivity in China. CHINA ECON REV 60, 101401

Xikai M, Lixiong W, Jiwei L, Xiaoli Q, Tongyao W (2019): Comparison of regression models for estimation of carbon emissions during building's lifecycle using designing factors: a case study of residential buildings in Tianjin, China. ENERG BUILDINGS 204, 109519

Yang X, Li N, Mu H, Pang J, Zhao H, Ahmad M (2021): Study on the long-term impact of economic globalization and population aging on CO2 emissions in OECD countries. SCI TOTAL ENVIRON 787, 147625

Yuewu Y, Ye L, Lei B, Wenxiang L (2016): Evolvement of the Center of Gravity for Road Freight Transport Carbon Emissions in China. Ecological Economy 32, 117-121

Zhang S, Li Z, Ning X, Li L (2021): Gauging the impacts of urbanization on CO2 emissions from the construction industry: Evidence from China. J ENVIRON MANAGE 288, 112440

Zhang X, Liu K, Zhang Z (2020): Life cycle carbon emissions of two residential buildings in China: Comparison and uncertainty analysis of different assessment methods. J CLEAN PROD 266, 122037

Zhang Y, Yan D, Hu S, Guo S (2019): Modelling of energy consumption and carbon emission from the building construction sector in China, a process-based LCA approach. ENERG POLICY 134, 110949

Zhao S, Song Q, Duan H, Wen Z, Wang C (2019): Uncovering the lifecycle GHG emissions and its reduction opportunities from the urban buildings: A case study of Macau. Resources, Conservation and Recycling 147, 214-226

Zhou C, Wang S, Wang J (2019): Examining the influences of urbanization on carbon dioxide emissions in the Yangtze River Delta, China: Kuznets curve relationship. SCI TOTAL ENVIRON 675, 472-482

Zhu B, Jiang M, Zhang S (2020): Resource and environment economic complex system: Models and applications. Science Press 